\title{
INVESTIGAÇÃO DE CITOCINAS DO SOBRENADANTE DE MACRÓFAGOS MURINOS ESTIMULADOS COM EPÍTOPOS PEPTÍDICOS DE LEISHMANIA (VIANNIA) BRAZILISIENSIS
}

\author{
A. A. da SILVA ${ }^{1}$, A. C. S. SANTOS ${ }^{1}$, R. de FREITAS E SILVA ${ }^{1,2}$, B. C. de OLIVEIRA ${ }^{1}$, M. \\ C. A. B. de CASTRO ${ }^{1,3}$, L. F. G. R. FERREIRA ${ }^{4}$, M. Z. HERNANDES ${ }^{4}$, O. P. de MELO \\ NETO $^{1}$; A. M. REZENDE ${ }^{1}$; V. R. A.PEREIRA ${ }^{1}$. \\ ${ }^{1}$ Instituto Aggeu Magalhães/Fiocruz-PE, 50.740-465, Cidade Universitária, Recife, PE, \\ Brasil. \\ ${ }^{2}$ Universidade de Pernambuco campus Garanhuns, 55294-902, Garanhuns,PE. \\ ${ }^{3}$ Universidade Federal de Pernambuco - Centro Acadêmico de Vitória (CAV), Vitória de \\ Santo Antão \\ ${ }^{4}$ Universidade Federal de Pernambuco campus Recife, Dept. de Ciências Farmacêuticas \\ E-mail para contato: ailtonsilvao@hotmail.com
}

\begin{abstract}
RESUMO - No grupo das doenças tropicais negligenciadas, as leishmanioses são destaque devido a sua ampla distribuição e a intensa ocorrência de novos casos ao ano. São causadas por protozoários do gênero Leishmania, transmitidos pela picada de flebótomos infectados. O tratamento é realizado administrando drogas que possuem diversas limitações entre toxicidade e surgimento de cepas resistentes do parasita. Considerando essas limitações, a vacinação se torna uma opção promissora para a realidade da doença, uma vez que é capaz de gerar memória imunológica, além de uma correta ativação do sistema imune. Portanto, o objetivo deste estudo foi avaliar a produção de citocinas do sobrenadante de macrófagos murinos, derivados de medula óssea (BMMØ), estimulados com epitopos vacinais de Leishmania (Viannia) braziliensis. Foram utilizadas células de medula óssea de camundongos BALB/, que foram diferenciadas para BMMØ pela adição de fator M-CSF. Esses macrófagos foram submetidos a estímulo com os peptídeos por $24 \mathrm{~h}$, sendo os sobrenadantes das culturas coletados. As citocinas, presentes no sobrenadante, foram investigadas por CBA e analisadas por citometria de fluxo. Os resultados indicaram produção de citocinas de perfis Th1 (TNF e IL-6) e Th2 (IL-10) e que alguns peptídeos se destacaram por induzir produção significativa dessas citocinas. Com isso, se faz necessário investigar quanto ao potencial terapêutico e profilático desses peptídeos.
\end{abstract}

Palavras-chave: Vacina. Leishmaniose. Epitopos vacinais.

ABSTRACT - In the group of neglected tropical diseases, leishmaniasis is highlighted due to its wide distribution and the intense occurrence of new cases per year. They are caused by protozoa of the genus Leishmania transmitted by the bite of infected sandflies. The treatment is carried out by administering drugs that have several limitations among toxicity and emergence of resistant strains of the parasite. Considering these limitations, vaccination becomes a promising option 
for the reality of the disease, since it can generate immune memory in addition to a correct activation of the immune system. Therefore, , the objective of this study was to evaluate cytokine production on bone marrow derived murine macrophages (BMMØ) supernatant, stimulated with vaccine epitopes of Leishmania (Viannia) braziliensis. Bone marrow cells were isolated from BALB / c mice bone marrow and differentiated into BMMØ by the addition of M-CSF factor. These macrophages were stimulated with peptides for $24 \mathrm{~h}$ and culture supernatants were collected. The cytokines present in the supernatant were investigated by CBA and analyzed by flow cytometry. The results indicate cytokine production of Th1 (TNF and IL-6) and Th2 (IL-10) profiles and that some peptides have been shown to induce significant production of these cytokines. Thus, it is necessary to investigate the therapeutic and prophylactic potential of these peptides.

Keywords: Vaccine. Leishmaniasis. vaccine epitopes.

\section{INTRODUÇÃ̃O}

As leishmanioses são um grupo de doenças tropicais negligenciadas (DTNs) amplamente distribuídas em cerca de 98 países, com estimativas de 2 milhões de novos casos de pessoas infectadas por ano (WHO 2015). A infecção ocorre pela transmissão de protozoários do gênero Leishmania, após a picada de fêmeas de flebótomos infectadas (MURRAY et al., 2005; SANGIORGI et al., 2012; WHO, 2015). De acordo com Carvalho et al. (2012) cerca de 20 espécies do gênero Leishmania provocam doenças em humanos, de modo que as manifestações clínicas são espécie-específica, podendo se apresentar como: tegumentar (LT), mucocutânea (LMC) ou visceral (LV), sendo a LT a forma clínica mais comum, segundo a WHO (2017). No Brasil, a LT é causada principalmente pela espécie $L$. (V.) braziliensis que provoca desde lesões cutâneas localizadas às desfigurantes lesões de mucosas (MUTISO et al. 2013).

O tratamento para as leishmanioses consiste na administração de antimoniais pentavalentes (GONTIJO 2003). Este tratamento exige a administração de diversas doses para atingir a concentração terapêutica, além de apresentar elevada toxicidade (SUNDAR E CHAKRAVARTY 2010), que acarreta na desistência do tratamento por parte do paciente, colaborando para o surgimento de cepas resistentes do parasita (MEHEUS et al. 2010; OLIVEIRA et al. 2011). Neste contexto, a vacinação surge como uma alternativa para o controle de todas as formas da doença (COSTA et al. 2011; KEDZIERSKI 2010).

A vacinação tem como proposta a correta ativação do sistema imunológico somada à geração de linfócitos de memória. A predominância da resposta de perfil Th1 está associada com a proteção contra a doença, enquanto que a predominância da resposta de perfil Th2 está ligada com a susceptibilidade e progressão da doença (Costa et al. 2011; Assis Souza et al. 2013). A eliminação do parasita, mediada pelo Th1, decorre principalmente por meio da ativação de macrófagos produtores de óxido nítrico, eliminando o parasita dentro da célula infectada. A prevalência do parasita mediada pelo perfil Th2 é decorrente da produção de anticorpos, que por sua vez sãos ineficientes no combate ao parasito (COSTA et al. 2011; MUTISO et al. 2013). Tendo em vista o importante papel dos macrófagos para a resolução da infecção por Leishmania spp. e a necessidade de entendimento da resposta imune frente ao parasita, este trabalho teve como intuito investigar a produção das principais citocinas envolvidas nas respostas Th1 e Th2 no sobrenadante de macrófagos murinos, estimulados com epítopos peptídicos do proteoma de Leishmania (Viannia) braziliensis. 


\section{MATERIAIS E MÉTODOS}

Aspectos éticos - Foram utilizados cinco camundongos BALB/c machos, com 6 a 8 semanas de idade. Os animais foram mantidos e alimentados sob os cuidados do biotério do Instituto de Pesquisas Aggeu Magalhães (IAM/FIOCRUZ-PE). Os protocolos utilizados no presente trabalho foram todos previamente analisados e aprovados pelo Comitê de Ética no Uso de Animais do IAM-FIOCRUZ (Processo CEUA 47/2013).

Obtenção de células-tronco murinas - Após a eutanásia dos animais em câmara de $\mathrm{CO}_{2}$, foi realizada a assepsia com álcool $70 \%$ seguida da extração dos fêmures e tíbias. As epífises dos ossos foram removidas e o canal medular foi lavado com meio RPMI 1640, utilizando seringas com agulha de $0,45 \mathrm{~mm}$ de diâmetro. A medula foi coletada, homogeneizada e em seguida filtrada em filtro de $0,45 \mathrm{~mm}$ de diâmetro. As células foram lavadas com meio RPMI 1640 (centrifugadas a 300 x g, por $10 \mathrm{~min}$ ), quantificadas em câmara de Neubauer, com auxílio de azul de Trypan, e sua concentração foi ajustada para $4-6 \times 10^{6}$ células $/ \mathrm{ml}$.

Diferenciação de macrófagos murinos derivados de medula óssea - A geração de macrófagos murinos derivados de medula óssea (BMMØ) foi seguindo o protocolo adaptado estabelecido por Weischenfeldt et al. (2008). As células de medula óssea foram distribuídas em placas de seis poços $\left(2 \times 10^{6}\right.$ células/poço). O meio de cultura utilizado foi composto por RPMI 1640, suplementado com $10 \%$ de SFB $+30 \%$ de sobrenadante de cultura de L929 e 1\% de antibiótico (Penicilina-Estreptomicina). O sobrenadante de L929 utilizado possui o fator de crescimento e diferenciação para macrófagos (M-CSF). O meio suplementado foi renovado nos terceiro e quinto dias a partir do início da cultura. No sétimo dia de cultivo as células estavam com morfologia características.

Estímulo de BMMØ com peptídeos de $L$. (V.) braziliensis - Ao fim da cultura de diferenciação, os macrófagos foram redistribuídos para placa de 24 poços na concentração correspondente a $2 \times 10^{6}$ células/poço. As células foram deixadas em repouso por duas horas para aderência a nova superfície, em seguida foi realizado o estímulo, com cada um dos 10 peptídeos na concentração de $20 \mu \mathrm{g} / \mathrm{ml}$ por 24 horas, realizado em duplicatas, separadamente para cada peptídeo testado. O sobrenadante foi coletado a cada intervalo de análise e armazenado em $-80^{\circ} \mathrm{C}$.

Dosagem de citocinas de sobrenadante de cultura - Os sobrenadantes de BMMØ foram descongelados e foi realizada a quantificação das citocinas: IFN-y, IL-2, IL-10, IL-4, TNF, IL-6, IL-17a utilizando o kit de CBA Th1, Th2, Th17 de camundongo (Cytometry Bead Array kit, BD Bioscience). Todos os procedimentos foram realizados de acordo com a recomendação do fabricante. Posteriormente, as amostras foram analisadas por citometria de fluxo num citômetro de fluxo FACScalibur. Para cada amostra, foram adquiridos 2.100 eventos conforme recomendado pelo fabricante. A curva padrão para o ensaio CBA foi determinada utilizando 9 diluições e os dados foram analisados com o software FCAP Array fornecido por BD Bioscience. Para a forma de análise estatística utilizou testes não-paramétricos de Kruskal-Wallis e Mann-Whitney. As diferenças foram consideradas estatisticamente significativas quando o valor de $p \leq 0,05$. 


\section{RESULTADOS E DISCUSSÃO}

Os resultados referentes ao estímulo de células BMMØ com os peptídeos de $L$. (V.) braziliensis demonstraram a detecção de três citocinas: TNF, IL-6 e IL-10. As demais citocinas testadas não atingiram valores significativos em relação ao controle não estimulado. Durante a detecção de TNF por essas células, observaram-se valores significativos nos peptídeos 2, 3 e 9, em relação ao controle não estimulado. Os níveis da citocina IL-6 apenas alcançaram valores significativos no peptídeo 8; entretanto, foi observado que esse peptídeo provocou uma "downregulation" dessa citocina, quando comparado ao controle. Os níveis observados da citocina IL-10 foi apenas detectado no peptídeo 2. Esse valor se mostrou significativo em comparação ao controle não estimulado. Em todos os resultados em BMMØ, nenhum dos peptídeos demonstrou valores significativos das citocinas avaliadas quando comparados ao controle estimulado com LPS.

Figura 1 - Níveis da citocina TNF no sobrenadante de BMMØ estimulados com peptídeos de $L$. ( $V$.) braziliensis durante $24 \mathrm{~h}$.

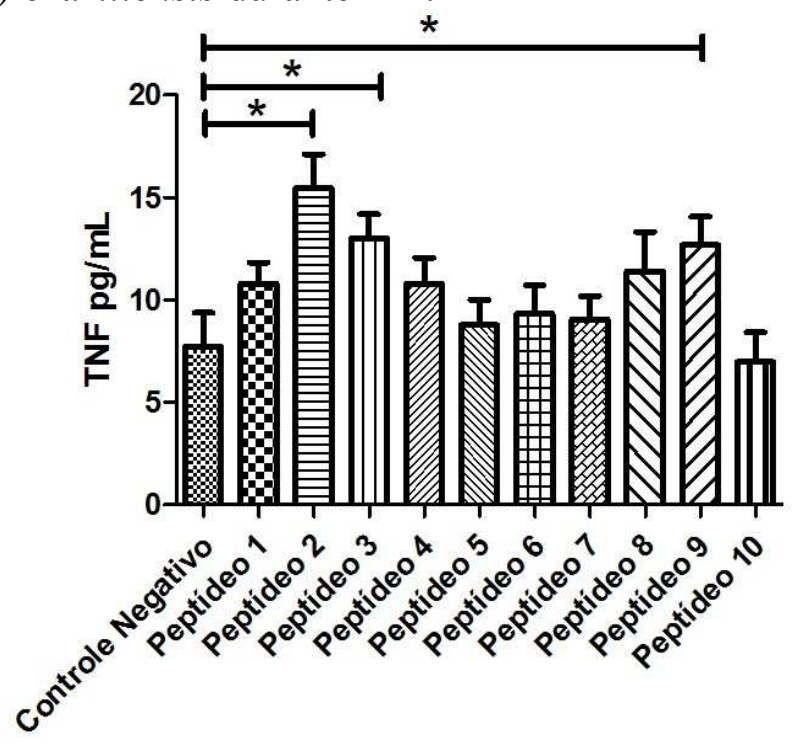

Nota: Os asteriscos representam os valores significantes de $p$ dos peptídeos em relação ao controle não estimulado: Peptídeo $2 p=0.0149$; Peptídeo $3 p=0.028$; Peptídeo $9 p=$ 0.0298 . 
Figura 2 - Níveis da citocina IL-6 no sobrenadante de BMMØ estimulados com peptídeos de $L$. (V.) braziliensis durante $24 \mathrm{~h}$.

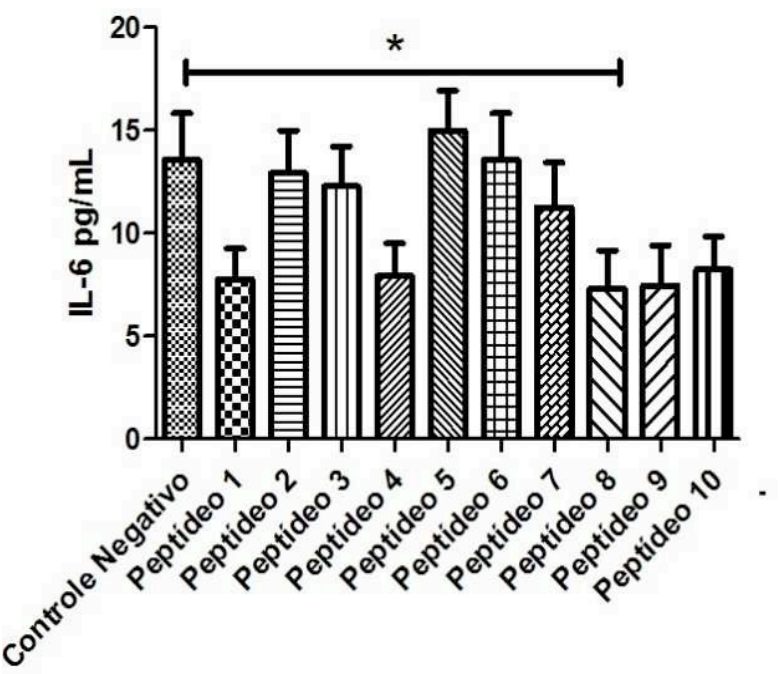

Nota: $\mathrm{O}$ asterisco representa o valor significante de $p$ do peptídeo em relação ao controle não estimulado: Peptídeo $8 p=0.029$.

Dentre as citocinas pró-inflamatórias, o TNF tem papel importante na ativação de macrófagos os quais passam a produzir espécies reativas e oxigênio e óxido nítrico, responsáveis pela eliminação do parasita (BOGDAN C. et al., 1990; GREEN SJ. et al., 1990). Por outro lado, altos níveis dessa citocina tem sido associada a uma resposta exacerbada da doença, com cronificação da lesão, o que ressalta a necessidade de um balanceamento na produção dessas citocinas pró-inflamatórias (WILHELM P. et al., 2001; VIEIRA LQ. et al., 1996; MELBY PC. et al., 1994; RIBEIRO DE JESUS A. et al., 2008). A IL-6 parece exercer um duplo papel como citocina pró-inflamatórias e também de prevenir os perfis de células $\mathrm{T}$ reguladoras que podem estar associados à exacerbação da doença (Kimura A. et al 2010; Costa DL. et al 2013). Em contrapartida, em modelos murinos IL-6-/- infectados com L. donovani se observou que a ausência dessa citocina refletia em uma resposta mais rápida contra o parasita, associada a um recrutamento de células mononucleares, e ao mesmo tempo uma resposta mais rápida e eficaz ao tratamento medicamentoso (HENRY W. MURRAY 2008).

Figura 3 - Níveis da citocina IL-10 no sobrenadante de BMMØ estimulados com peptídeos de $L$. (V.) braziliensis durante $24 \mathrm{~h}$.

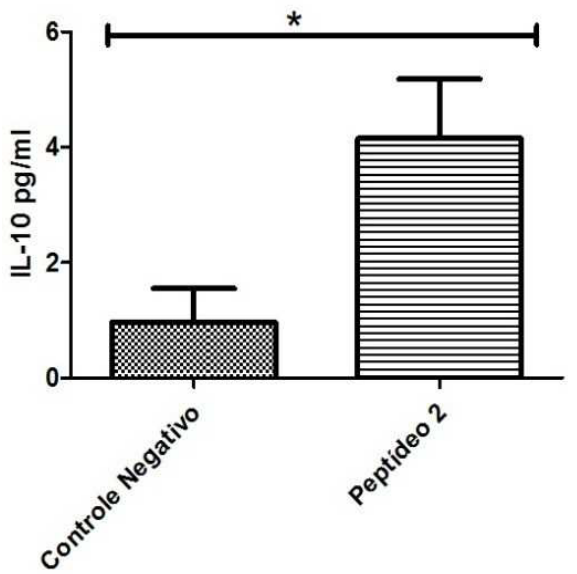


Nota: $\mathrm{O}$ asterisco representa o valor significante de $p$ do peptídeo em relação ao controle não estimulado: Peptídeo $2 p=0.028$.

Citocinas do perfil Th2, principalmente IL-10, tem sido relacionadas com alta carga parasitária, e efeitos de imunossupressão, como inibição da produção de óxido nítrico por macrófagos ativados por IFN- $\gamma$, bem como inibição da diferenciação de linfócitos Th1 (GAUTAM et al. 2011; VARGAS-INCHAUSTEGUI et al. 2013).

De modo geral, foi observado que os peptídeos de $L$. (V.) braziliensis avaliados são capazes também de estimular produção de TNF em macrófagos murinos. É importante considerar que deve haver um equilíbrio entre as citocinas de perfis próinflamatórios (como TNF e IL-6) e anti-inflamatórios (como IL-10), agindo em conjunto para induzir uma resposta imune protetora e promover um balanceamento dessa resposta, como já bem descrito na literatura (KAYE; SCOTT, 2011; SCOTT; NOVAIS, 2016). Esses achados sustentam o potencial desses peptídeos na abordagem de vacinação para LT. É esperado que uma vacina ideal contra LT induza corretamente células T de memória, e uma resposta anti-Leishmania mediada por uma imunobalanço Th1 / Th2, como destacado por Bertholet S, et al. (2009) e Nagill R. et al. (2011).

\section{CONCLUSÃO}

Os resultados apresentados podem sugerir o potencial terapêutico e profilático desses peptídeos, uma vez que são capazes de induzir tanto um perfil Th1 quanto uma regulação promovida por um perfil Th2. Esses achados são promissores para o avanço na pesquisa de uma vacina segura e eficaz para LT. Ademais, é necessário que esse potencial deva ser mais bem investigado para melhor esclarecimento do papel desses peptídeos.

\section{REFERÊNCIAS}

BERTHOLET, S. et al. Optimized subunit vaccine protects against experimental leishmaniasis. Vaccine, v. 27, n. 50, p. 7036-7045, 2009.

CARVALHO, L. P. et al. Protective and pathologic immune responses in human tegumentary leishmaniasis. Frontiers in Immunology, v. 3, n. OCT, p. 1-9, 2012.

COSTA, C. H. N. et al. Vaccines for the leishmaniases: proposals for a research agenda. PLoS neglected tropical diseases, v. 5, n. 3, p. e943, jan. 2011.

COSTA, D. L. et al. Characterization of regulatory T cell (Treg) function in patients infected with Leishmania braziliensis. Human Immunology, v. 74, n. 12, p. 1491-1500, 2013.

DE ASSIS SOUZA, M. et al. Cytokines and NO in American tegumentary leishmaniasis patients: Profiles in active disease, after therapy and in self-healed individuals. Microbial Pathogenesis, v. 57, p. 27-32, 2013.

GAUTAM, S. et al. IL-10 neutralization promotes parasite clearance in splenic aspirate cells from patients with visceral leishmaniasis. Journal of Infectious Diseases, v. 204, n. 7, p. 1134-1137, 2011. 
GONTIJO, B. Leishmaniose tegumentar americana American cutaneous leishmaniasis. Medicina Tropical, v. 36, n. 13, p. 71-80, 2003.

KAYE, P.; SCOTT, P. Leishmaniasis: complexity at the host-pathogen interface. Nature reviews. Microbiology, v. 9, n. 8, p. 604-615, 2011.

KEDZIERSKI, L. Leishmaniasis Vaccine: Where are We Today? Journal of global infectious diseases, v. 2, n. 2, p. 177-85, 2010.

KIMURA, A.; KISHIMOTO, T. IL-6: Regulator of Treg/Th17 balance. European Journal of Immunology, v. 40, n. 7, p. 1830-1835, jul. 2010.

MEHEUS, F. et al. Cost-effectiveness analysis of combination therapies for visceral leishmaniasis in the Indian subcontinent. PLoS Neglected Tropical Diseases, v. 4, n. 9, 2010 .

MELBY, P. C. et al. Increased expression of proinflammatory cytokines in chronic lesions of human cutaneous leishmaniasis. Infection and immunity, v. 62, n. 3, p. 83742, mar. 1994.

MURRAY, H. W. et al. Advances in leishmaniasis. [Review]. Lancet, v. 366, n. 9496, p. 1561-1577, 2005.

MURRAY, H. W. Accelerated control of visceral Leishmania donovani infection in interleukin-6-deficient mice. Infection and Immunity, v. 76, n. 9, p. 4088-4091, 2008.

MUTISO, J. M. et al. Development of Leishmania vaccines: predicting the future from past and present experience. Journal of biomedical research, v. 27, n. 2, p. 85-102, 2013.

NAGILL, R.; KAUR, S. Vaccine candidates for leishmaniasis: A review. International Immunopharmacology, v. 11, p. 1464-1488, 2011.

OLIVEIRA, L. F. et al. Systematic review of the adverse effects of cutaneous leishmaniasis treatment in the New World. Acta Tropica, v. 118, n. 2, p. 87-96, 2011.

RIBEIRO DE JESUS, A. et al. Pentoxifylline down modulate in vitro T cell responses and attenuate pathology in Leishmania and HTLV-I infections. International Immunopharmacology, v. 8, n. 10, p. 1344-1353, 2008.

SANGIORGI, B. et al. Natural breeding places for phlebotomine sand flies (Diptera: Psychodidae) in a semiarid region of Bahia State, Brazil. Journal of Tropical Medicine, v. 2012, 2012.

SCOTT, P.; NOVAIS, F. O. Cutaneous leishmaniasis: immune responses in protection and pathogenesis. Nature Publishing Group, 2016.

SUNDAR, S.; CHAKRAVARTY, J. Antimony toxicity. International Journal of Environmental Research and Public Health, v. 7, n. 12, p. 4267-4277, 2010.

VARGAS-INCHAUSTEGUI, D. A.; XIN, L.; SOONG, L. Protective Immune Responses 1. 2013. 
VIEIRA, L. Q. et al. Mice lacking the TNF receptor p55 fail to resolve lesions caused by infection with Leishmania major, but control parasite replication. Journal of immunology (Baltimore, Md. : 1950), v. 157, n. 2, p. 827-35, jul. 1996.

WEISCHENFELDT, J.; PORSE, B. Bone marrow-derived macrophages (BMM): Isolation and applications. Cold Spring Harbor Protocols, v. 3, n. 12, p. 1-7, 2008.

WHO. WHO | Leishmaniasis., 2015.

WHO. WHO - Leishmaniasis. 2017.

WILHELM, P. et al. Rapidly fatal leishmaniasis in resistant C57BL/6 mice lacking TNF. Journal of immunology (Baltimore, Md. : 1950), v. 166, n. 6, p. 4012-9, mar. 2001.

\section{AGRADECIMENTOS}

Agradecimentos à Fundação de Amparo à Ciência e Tecnologia do Estado de Pernambuco (FACEPE) pela concessão da bolsa de iniciação científica. Ao Instituto Aggeu Magalhães, FIOCRUZ-PE pela infraestrutura fornecidas. Às agências de fomento, Conselho Nacional de Pesquisa Científica (CNPq) e FACEPE, pelo apoio financeiro ao projeto para realização desse trabalho. 